\title{
RETRACTED ARTICLE: Freshwater fish biodiversity of India: pattern, utilization, importance, threats and challenges
}

\author{
U. K. Sarkar $\cdot$ V. K. Dubey · J. K. Jena
}

Received: 3 November 2012/ Accepted: 27 February 2013/Published online: 12 March 2013

(C) Springer Science+Business Media Dordrecht 2013

This article has been retracted at the request of the Publisher and Editor-in-Chief due to a violation of Springer's Publishing Principles as part of the content of the article 10.1007/s11160-013-9306-x has been duplicated from different research papers. The authors apologize to the Editors and readers as well as the authors of the original papers.

U. K. Sarkar $(\bowtie) \cdot$ V. K. Dubey · J. K. Jena

National Bureau of Fish Genetic Resources, Canal Ring Road, P.O. Dilkusha, Lucknow 226 002, Uttar Pradesh, India

e-mail: usarkar1@rediffmail.com; uksarkar1@gmail.com 